\title{
USING A PARAMETRIC STUDY TO ANALYSE THE PERFORMANCE OF WOOD SOLAR DRYERS WITH GLAZED WALLS
}

\author{
Naoual Bekkioui ${ }^{1, \star}$, André Zoulalian $^{2}$, Abdelillah Hakam³, Hamid EZ-Zahraouy ${ }^{1}$
}

\begin{abstract}
Parameters characterizing wood and air were studied in order to analyze the performance of a wood solar dryer functioning under Moroccan climate. A mathematical model based on the climate data of Rabat city was used to investigate theoretically the wood drying process. Two wood speciesthuya (Tetraclinis articulate) and pine (Pinus pinaster)-were examined in the present study. The results obtained by computer simulations are in good agreement with the experimental values. Furthermore, our findings indicate that the use of a global mass transfer coefficient for low temperature convective and homogenous drying conditions allows the influence of the principal operating parameters (wood thickness, wood density, air temperature, air velocity and ventilation mode) on the drying time to be estimated with great accuracy. Analyses pertaining to the two studied wood species revealed that(1) pine dries more quickly than thuya, (2) the drying process is faster in the summer relative to other seasons, (3) increasing the air velocity by $100 \%$ results in a $20 \%$ reduction in the drying time, and (4) continued ventilation reduces the drying time by $43 \%$.
\end{abstract}

Keywords: Drying curves, drying operating parameters, drying time, mass transfer coefficient, solar drying.

\section{INTRODUCTION}

As our extant research shows, parametric studies of wood solar drying can result in improvements in the energy efficiency of solar dryers. In our previous works, we have developed a mathematical model using two approaches for the mass transfer coefficient of water in wood and the surrounding air (Bekkioui et al. 2009, Bekkioui et al. 2011). The developed model was subsequently subjected to a comparative study, whereby it was applied to the data pertaining to two drying cycles performed on two wood species in two different Moroccan climates. The findings yielded confirmed close agreement between the model-predicted and measured results, thereby ascertaining model accuracy. Nevertheless, in order to evaluate the effect of the operating parameters, in this work, we have conducted a parametric study, as this allows the model to be used as an effective tool for optimizing the solar drying process.

Our work is also motivated by the potential for commercializing the solar dryers in the wood drying sector in Morocco, where the use of solar energy for wood drying is presently limited to the experimental investigations only. Only few wood solar dryers have been realized in practice, with limited success (Youssefi 1997, El kannafi 2002). However, as drying is one of the most important operations in the wood industry, solar drying has a great potential, as the energy required, which can be substantial, is readily available. According to Pirasteh et al. (2014), approximately $40 \%$ to $70 \%$ of

${ }^{1}$ Laboratoire de Matière Condensée et Sciences Interdisciplinaires (LaMCScI), Faculty of Sciences P.O.Box 1014, Mohammed V University of Rabat, Morocco.

${ }^{2}$ LERMAB - Université de Nancy 1, Vandoeuvre les Nancy, France.

${ }^{3}$ Wood Science Laboratory, Mohammed V University, Faculty of Sciences, Rabat, Morocco.

•Corresponding author: bekkioui_naoual@yahoo.fr

Received: 16.01.2017 Accepted: 08.07.2017 
the total energy consumed in the wood product industry pertains to wood drying processes. Against this backdrop, solar dryers are a viable option for many countries, as they can limit dependency on fuel and electricity that power conventional dryers (Hasan and Langrish 2014, Hasan and Langrish 2015). Also, there has been extensive evidence indicating that solar dryers are particularly relevant for the developing countries, as many suffer energy shortage (Helwa et al. 2004, Bentayeb et al. 2008, Luna et al. 2010, Simo-Tagne et al. 2017).

As solar energy inputs can be unpredictable due to the changes in weather conditions, their variability can be evaluated through mathematical modeling. A numerical simulation of a solar dryer for drying timber was conducted by Hasan and Langrish (2015), where three particular Australian locations were considered. They mentioned that the prospect of better productivity and quality in the end product depend on geographical locations and climatic conditions. Morocco is a Mediterranean country with a diverse climate. While it is generally hot and dry most of the year, temperatures decline sharply in winter, especially in December and January. Fall and spring seasons last about two months each. The summer days are long, with 15 to 16 hours of sunlight per day, compared to only 6 to 8 hours during the winter (Buret et al. 1983). In this work, we took into account the climatic conditions characterizing each of the four seasons in the modeling, as the results yielded allow us to improve the solar drying process, as well as ensure that the model is applicable for a wide range of environmental conditions.

In sum, the aim of the present study was to investigate theoretically the effect of the operating parameters on the drying process and compare the results with the experimental data and findings reported in pertinent literature.

\section{MATERIALS AND METHODS}

The dryer examined in the present study is a greenhouse solar dryer for wood, a thermodynamic system in which air serves as the drying agent. The sloping roof and three walls (south-, east- and west-facing) are single-glazed, thus permitting transmission of solar radiation into the dryer. The northfacing wall is well insulated and incorporates a door to admit the wood load. To move the warm air through the dryer, an electric fan is placed above the wood stack and the evacuation of humid air towards the exterior is achieved by manually opening and closing vents perforated on the northern wall. The detailed description of this dryer is given by Bekkioui et al. (2009).

The simulation was performed using the mathematical model developed by Bekkioui et al. (2009). In this model, each element of the dryer is assigned a corresponding temperature, while taking into account the variation in the wood moisture content in equilibrium with the moisture content of the surrounding air. For the mass balance of water in the solid phase (wood), the first approach given by Bekkioui et al. (2011) was adopted to evaluate the mass transfer coefficient:

$$
M_{0} \frac{d X}{d t}=-K_{e} S_{b}\left(X-X^{*}\right)
$$

The global mass transfer coefficient is given by the following correlation (Chrusciel et al. 1999):

$$
\frac{1}{K_{e}}=a_{0} \exp \left(\frac{c_{0}}{T_{a}}\right) \cdot e+b_{0} \exp \left(\frac{c_{0}}{T_{a}}\right) \cdot v^{-p} \exp \left(-\frac{z}{X_{F S P}-X^{*}}\right)
$$




$$
a_{0}=0,2265 ; \quad b_{0}=268,9 ; \quad c_{0}=2543,6 \quad p=2,7158 ; \quad \mathrm{z}=1-\frac{R H}{100}
$$

To calculate theoretically either the global mass transfer coefficient or the moisture movement coefficient related to thuya during the drying cycle, while solving the model equations, we have also utilized the second approach given by Bekkioui et al. (2011). The rate of water movement in wood suggested in the second approach is described by the following equation:

$$
\frac{d X}{d t}=-\frac{K}{e}\left(X-X^{*}\right)
$$

where the moisture movement coefficient $K$ is given by Taylor et al. (1985):

$$
K\left(\rho_{0}, T_{a}\right)=K_{0 a} \frac{W_{s a t}\left(T_{a}\right)}{W_{s a t}\left(T_{0 a}\right)} \frac{\rho_{0 a}}{\rho_{0}}
$$

In the expression above, $K_{0}=3,88 \times 10^{-8} \mathrm{~m} \cdot \mathrm{s}^{-1}$ denotes the moisture movement coefficient for mahogany (Swietenia macrophylla) of basic density $\rho_{0 \mathrm{a}}=440 \mathrm{~kg} \cdot \mathrm{m}^{-3}$ at temperature $T_{0 a}=30^{\circ} \mathrm{C}$, and $\rho_{0}$ is the basic density of the wood being analyzed.

The metrological data used in the simulation pertain to the city of Rabat $\left(34^{\circ} \mathrm{N}, 7^{\circ} \mathrm{W}\right)$. The calculations were carried out for the drying process that commences at the $35 \%$ initial wood moisture content and terminates at $15 \%$. In addition, ventilation is operated from 10 am to 4 pm every day during the drying cycle.

\section{RESULTS AND DISCUSSION}

The model-predicted moisture content evolution for $27 \mathrm{~mm}$ thick boards of thuya is presented in Figure 1. As can be seen from the data, 366 hours of drying time is necessary for reducing the wood moisture content from $35 \%$ to $15 \%$. In addition, similar drying curve is obtained (with less than $2 \%$ difference) regardless of whether the global mass transfer coefficient $K_{e}$ evaluated by applying equation (2) or the moisture movement coefficient $K$ obtained via equation (4) for the mass balance of water in thuya is used.

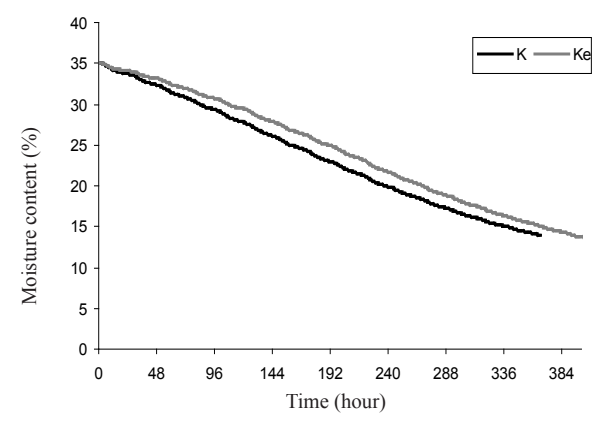

Figure 1. Predicted moisture content evolution of $27 \mathrm{~mm}$ thick boards of thuya. 
The $K_{e}$ and $K$ values obtained by the model for thuya during drying follow similar curves (Figure 2 ), which are closely aligned with the air temperature inside the dryer (Figure 5). Both coefficients increase during the day time and decrease at night. More specifically, the $K$ values vary daily between $2 \times 10^{-8} \mathrm{~m} \cdot \mathrm{s}^{-1}$ and $6 \times 10^{-8} \mathrm{~m} \cdot \mathrm{s}^{-1}$, while the $K_{e}$ values are in the $2 \times 10^{-6}-1,7 \times 10^{-5} \mathrm{~kg} \cdot \mathrm{m}^{-2} \cdot \mathrm{s}^{-1}$ range, with the difference of about $6,5 \times 10^{-6} \mathrm{~kg} \cdot \mathrm{m}^{-2} \cdot \mathrm{s}^{-1}$ between the day and the night levels.

However, these values could not be experimentally validated due to the lack of data. Thus, the values pertaining to another resinous wood are provided here for information purposes only. For an air relative humidity equal to $50 \%$ and an air temperature in the $40^{\circ} \mathrm{C}-50^{\circ} \mathrm{C}$ range, the experimental values of $K$ related to spruce (Picea abies) were reported to vary from $4 \times 10^{-8}$ to $5,6 \times 10^{-8} \mathrm{~m} . \mathrm{s}^{-1}$ (Villiere 1966). For the same air temperature, $70 \%$ air relative humidity and 3,5m. $\mathrm{s}^{-1}$ air velocity, Chrusciel (1998) obtained the experimental values of $K$ in the $4,5 \times 10^{-5}-4,73 \times 10^{-5} \mathrm{~kg} \cdot \mathrm{m}^{-2} \cdot \mathrm{s}^{-1}$ range. These results indicate that, although the operational conditions are not similar, the predicted values of $K$ and $K_{e}$ for thuya are comparable to the experimental results obtained for spruce.
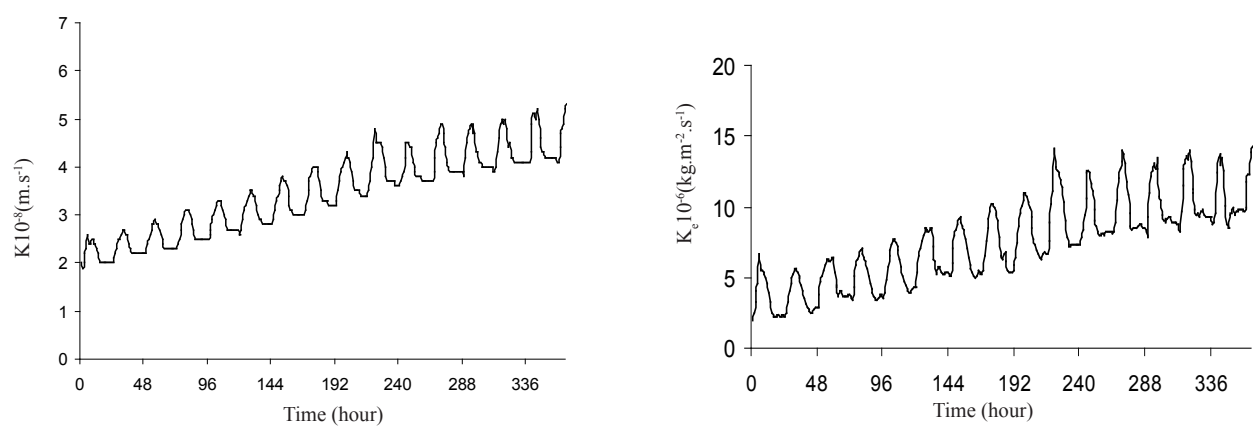

Figure 2. $K$ and $\mathrm{Ke}$ values of $27 \mathrm{~mm}$ thick boards of thuya.

Predicted moisture content of thuya for $54 \mathrm{~mm}$ and $27 \mathrm{~mm}$ thick boards is presented in Figure 3 . As can be seen from the results, the thicker boards require 336 hours to dry from $35 \%$ to $21 \%$ moisture content, compared to only 220 hours for the thinner ones.

As the increasing gap between the two curves suggests, the effect of wood thickness is more prominent for wood with lower moisture content. According to the model results, when the wood thickness is doubled, the drying time increases by a factor of 1,7. Figure 3 shows that the values of the global mass transfer $K_{e}$ are higher for the wood of $27 \mathrm{~mm}$ relative to $54 \mathrm{~mm}$ thickness. This finding is in good agreement with the published results, as the conductance $\left(1 / K_{e}\right)$ is a linear function of wood thickness (Chrusciel et al. 1999).
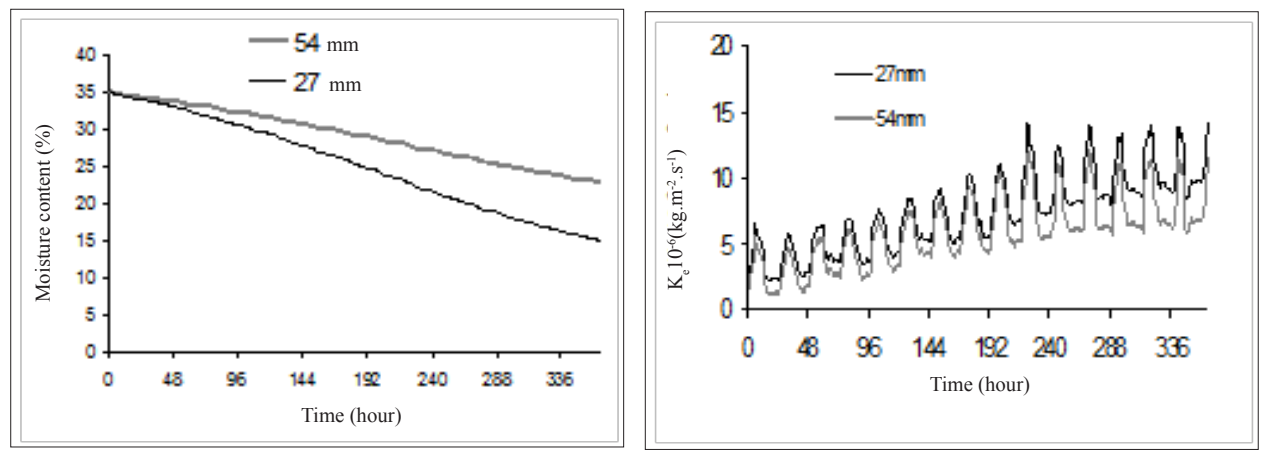

Figure 3. Effect of thickness. 
Predicted moisture content for two wood species (pine and thuya) is reported in Figure 4. As can be seen from the graphs, a satisfactory agreement between the predicted and the measured values has been achieved. In addition, both model results and experimental data indicate that, due to its smaller density $\left(450 \mathrm{~kg} \cdot \mathrm{m}^{-3}\right)$ pine dries more quickly than thuya (at $\left.520 \mathrm{~kg} \cdot \mathrm{m}^{-3}\right)$. This is in line with the values reported by Simpson (1991), who noted that the diffusion coefficient of water in wood is inversely proportional to wood density. Hence, under similar operational conditions, pine would dry faster than would thuya.

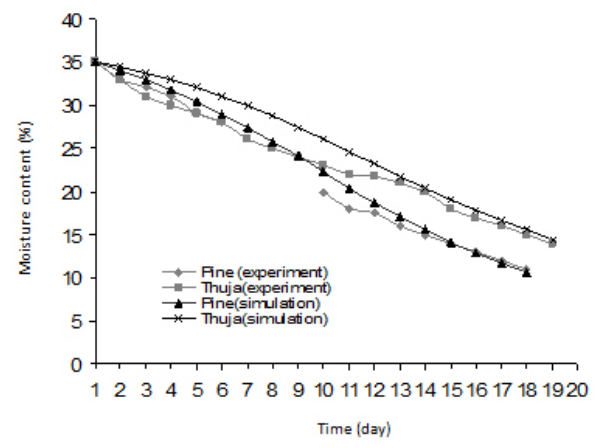

Figure 4. Effect of species.

The drying process depends not only on the wood properties, but also on the characteristics of air as the drying agent, its temperature in particular. For wood solar dryers, it is not possible to study the air temperature influence without considering the weather conditions. Thus, the climatic data related to four seasons were used as inputs into the simulation program. Each season of the year was represented by a particular month, i.e., January (winter), April (spring), July (summer) and October (fall).

Figure 5 shows that the drying process is the fastest in summer, as the solar radiation is being supplied to the dryer through the roof and all three glazed walls. Moreover, as ambient temperature is higher in July and October than in January and April (Bekkioui 2009) the air temperature inside the dryer is more important in summer and fall than in winter and spring (Figure 5).
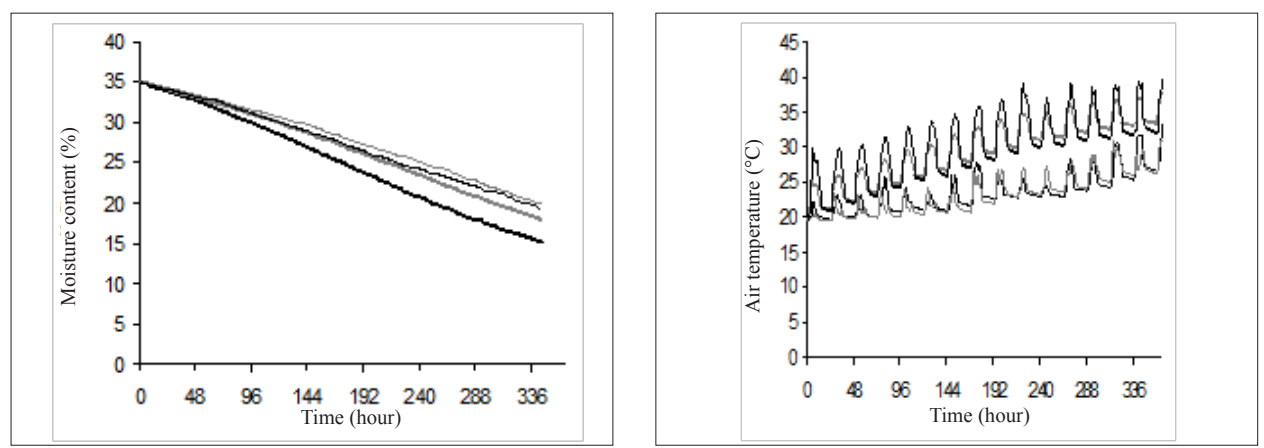

Figure 5. Effect of varying weather ( _ Jvly, _ October, _ January, _ April)

We have run the simulation program with two values of air velocity in order to assess the influence of this parameter on both the global mass transfer coefficient $K_{e}$ and the convective heat transfer coefficient between wood and the surrounding air.

As can be seen from Figure 6, when the air velocity increases from $1 \mathrm{~m} \cdot \mathrm{s}^{-1}$ to $2 \mathrm{~m} \cdot \mathrm{s}^{-1}$, the same drying time results in a greater reduction in moisture content ( $35 \%$ to $15 \%$ vs. $35 \%$ to $10 \%$ ). This result can be explained by the increase in the convective heat transfer coefficient from $6 \mathrm{~W} \cdot \mathrm{m}^{-2} \cdot \mathrm{K}^{-1}$ to $11 \mathrm{~W} \cdot \mathrm{m}$ ${ }^{2} \cdot \mathrm{K}^{-1}$ as the air velocity increases from $1 \mathrm{~m} \cdot \mathrm{s}^{-1}$ to $2 \mathrm{~m} \cdot \mathrm{s}^{-1}$ and the corresponding increase in the $K_{e}$ values (Figure 6). 

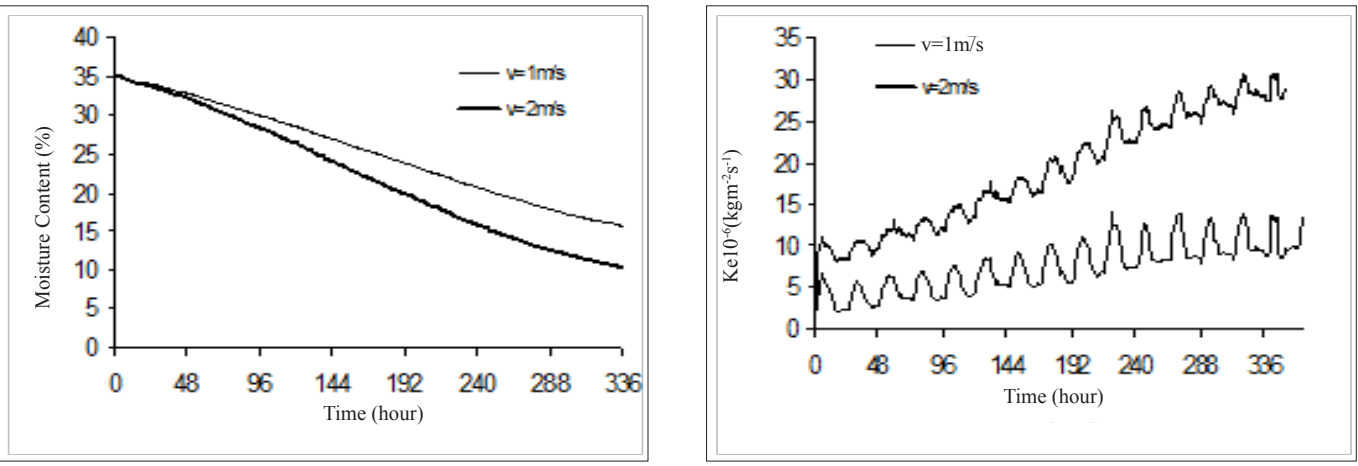

Figure 6. Effect of air velocity.

For economic reasons, it is common to use the electric fan of the dryer during the day only, as it is more critical to evacuate the humid air when its moisture content is much greater than that of the wood. Thus, we analyzed the effect of two ventilation modes on the drying time. Figure 7 shows that keeping the vents opened at night with the electric fan switched on results in a $43 \%$ reduction in the drying time compared to that when the fan is switched off.

Figure 7 present also air temperatures $(T a)$ and relative humidity $(R H)$ inside the dryer for the two ventilation types. It can be noted that keeping the vents opened at night with the electric fan switched on results in a decline in air temperature and relative humidity inside the dryer compared to that when the fan is switched off. We can conclude that, although ventilating the dryer made it cooler, the drying time is reduced because the humid air is efficiently removed.
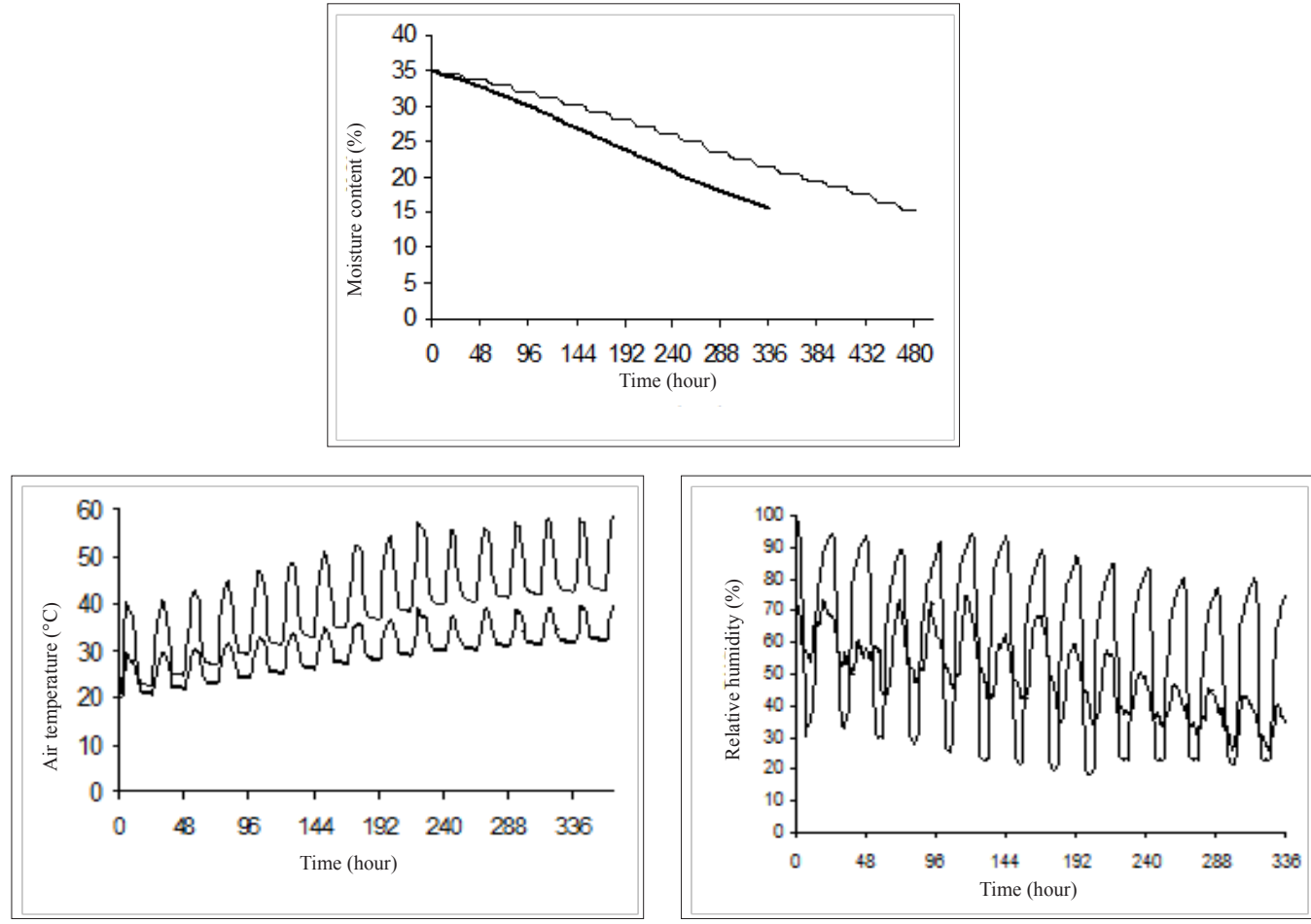

Figure 7. Effect of the ventilation mode fan switched on at night, fan switched off at night) 
Of course, switching on the fan at night will increase the electric consumption of the dryer; however, as it will reduce the drying time by $50 \%$ it may be economically viable. Indeed, Elkannafi (2002) calculated that $14 \$ / \mathrm{m}^{3}$ was required for drying thuya when the dryer was ventilated during the day only, compared to $10 \$ / \mathrm{m}^{3}$ when the ventilation was permanently switched on. These experimental findings confirm that it is more economically viable to operate the dryer's electric fan continuously throughout the drying period.

\section{CONCLUSIONS}

In this work, global mass transfer coefficient for low temperature convective and homogeneous wood dryers was used to evaluate separately the influence of the operating parameters characterizing wood and air on the drying time. As the findings reported in this paper show, the drying time increases with the wood thickness and density, while it decreases with air temperature and continued venting. The findings yielded by this theoretical investigation are in good agreement with both experimental data and the results reported in pertinent literature, confirming that the developed model and the global mass transfer coefficient used in the present study can serve as useful tools for improving solar wood dryer performance.

\section{REFERENCES}

Bekkioui, N.; Hakam, A.; Zoulalian, A.; Sesbou, A.; Elkortbi, M.E. 2011. Solar drying of pine lumber: Verification of a mathematical model. Maderas-Cienc Tecnol 13(1): 29-40.

Bekkioui, N.; Zoulalian, A.; Hakam, A.; Bentayeb, F.; Sesbou, A. 2009. Modelling of a wood solar dryer with glazed walls. Maderas-Cienc Tecnol 11(3): 191-205.

Bekkioui, N. 2009. Séchage solaire du bois: Modélisation simplifiée du séchage d'une pile de bois dans un séchoir solaire à parois vitrées. Thése de Doctorat. Faculty of Sciences of Rabat.

Bentayeb, F.; Bekkioui, N.; Zeghmati, B. 2008. Modelling and simulation of a wood solar dryer in a Moroccan climate. Renewable Energy 33: 501-506.

Buret, J.; Bargach, M. N.; Benkadour, M.L. 1983. Le gisement solaire Marocain. Collection Sciences. Société Marocaine des Editeurs Réunis (SMER).

Chrusciel, L.; Mougel, E.; Zoulalian, A.; Meunier, T. 1999. Characterisation of water transfer in a low temperature convective wood drier: influence of the operating parameters on the mass transfer coefficient. Holz als Roh und Werkstoff 57: 439-445.

Chrusciel, L. 1998. Etude de l'association d'une colonne d'absorption à un séchoir convectif à basse température. Influence de l'absorbeur sur la cinétique et la qualité du séchage. Thèse de Doctorat de l'Institut National Polytechnique de Lorraine-Nancy.

EI kannafi, A. 2002. Etude de la faisabilité du séchage solaire du bois de Thuya dans la ville d'Essaouira. Mémoire de 3ème cycle. Ecole Nationale Forestière d'Ingénieurs.

Hasan, M.; Langrish, T.A.G. 2015. Performance comparison of two solar kiln designs for wood drying using a numerical simulation. Drying Technology 33(6): 634-645.

Hasan, M.; Langrish, T.A.G. 2014. Numerical simulation of a solar kiln design for drying timber with different geographical and climatic conditions in Australia. Drying Technology 32(13): 16321639 .

Helwa, N.H.; Khater, H.A.; Enayet, M.N.; Hashish, M.I. 2004. Experimental Evaluation of Solar Kiln for Drying Wood. Drying Technology 22(4):703-717. 
Luna, D.I.; Nadeau, J.P.; Jannot, Y. 2010. Model and simulation of a solar kiln with energy storage. Renewable Energy 36(11): 2533-2542.

Pirasteh, G.; Saidur, R.; Rahman, S.M.A.; Rahim, N.A. 2014. A review on development of solar drying applications. Renewable and Sustainable Energy Reviews 31: 133-148

Simo-Tagne, M.; Zoulalian, A.; Remond, R.; Rogaume, Y.; Bonoma, B. 2017. Modelling and simulation of an industrial indirect solar dryer for Iroko wood (chlorophora excelsa) in a tropical environment. Maderas-Cienc Tecnol 19(1): 95-112.

Simpson, W.T. 1991. Dry Kilns Operator's Manuel, USDA, Forest service, Madison, Wisconsin. Agriculture Handbook 188.

Taylor, K.J.; Weir, A.D. 1985. Simulation of solar timber dryer. Solar Energy 34 (3): 249-255.

Villiere, A. 1966. Séchage des bois. Sixième Edition. Dunod-Paris.

Youssefi, M. 1997. Le séchage du bois au Maroc, construction et expérimentation d'un séchoir solaire pilote. Mémoire de 3ème cycle. IVA Hassan II, Rabat.

NOMENCLATURE

\begin{tabular}{|l|c|}
\hline$R H:$ relative humidity & $\%$ \\
\hline$K:$ moisture movement coefficient & $\mathrm{m} \cdot \mathrm{s}^{-1}$ \\
\hline$K_{e}:$ global mass transfer coefficient wood water - gas water & $\mathrm{kg} \cdot \mathrm{m}^{-2} \cdot \mathrm{s}^{-1}$ \\
\hline$M_{0}:$ oven dry mass of the wood & $\mathrm{kg}$ \\
\hline$S_{b}:$ exchange surface between the wood stack and the drying air & $\mathrm{m}$ \\
\hline$T_{a}:$ air temperature & $\mathrm{K}$ \\
\hline$W_{\text {sat }}:$ saturated humidity of drying air & $\mathrm{kg} \cdot \mathrm{kg}^{-1}$ \\
\hline$X:$ moisture content of wood & $\mathrm{kg} \cdot \mathrm{kg}^{-1}$ \\
\hline$X_{0}:$ initial moisture content of wood & $\mathrm{kg} \cdot \mathrm{kg}^{-1}$ \\
\hline$X^{*}:$ equilibrium moisture content of wood (EMC) & $\mathrm{kg} \cdot \mathrm{kg}^{-1}$ \\
\hline$X_{P S F}:$ moisture content of wood at Fiber Saturation Point & $\mathrm{kg} \cdot \mathrm{kg}^{-1}$ \\
\hline$e:$ wood thickness & $\mathrm{m}$ \\
\hline$v:$ air velocity & $\mathrm{m} \cdot \mathrm{s}^{-1}$ \\
\hline $\boldsymbol{\rho}_{0}:$ basic density of wood & $\mathrm{kg} \cdot \mathrm{m}^{-3}$ \\
\hline
\end{tabular}

